\title{
Laboratory Information Management System
}

National Cancer Institute

\section{Source}

National Cancer Institute. Laboratory Information Management System. NCI Thesaurus.

Code C48209.

Integ rated computer systems that are used in the laboratory for the management of samples, laboratory users, instruments, standards and other laboratory functions such as invoicing, plate management, and work flow automation. 